\title{
XII SIMPÓSIO BRASILEIRO DE GEOGRAFIA FÍSICA APLICADA - SBGFA - 2007
}

\author{
Emerson Galvani* \\ Nádia Gilma Beserra de Lima**
}

\begin{abstract}
O XII Simpósio Brasileiro de Geografia Física Aplicada (XII SBGFA) ocorreu na Universidade Federal do Rio Grande do Norte (UFRN), na cidade de Natal, entre os dias 09 a 13 de julho de 2007. O evento foi organizado pelo Departamento de Geografia do Centro de Ciências Humanas, Letras e Artes - CCHLA da UFRN-Natal. A coordenação geral do evento ficou a cargo do professor Dr. Elias Nunes e da professora Dra. Maria do Socorro Costa Martim, contando com a participação dos alunos de Graduação em Geografia da instituição. Intitulado de "Natureza, Geotecnologia, Ética e Gestão do Território", o evento, de acordo com os organizadores, teve como objetivo "estimular a apresentação de resultados de pesquisas e a discussão de temas referentes aos problemas urbanos, agrários, turismo, reações da natureza, cartografia temática, ensino e modelos em geografia física e geotecnologias. Contempla, também, debates teórico-metodológicos buscando aprofundar as reflexões relativas ao pensamento geográfico, a epistemologia, a gestão do território e a ética profissional."(Comissão Organizadora, 2007).
\end{abstract}

o evento contou com o apoio da Coordenadoria de Aperfeiçoamento de Pessoal de Nível Superior (CAPES), Conselho Nacional de Desenvolvimento Nacional Científico e Tecnológico $(\mathrm{CNPq})$, Fundação de Amparo a Pesquisa do Estado do Rio Grande do Norte (FAPERN), Petróleo Brasileiro S.A. (PETROBRÁS), Associação de Geógrafos Brasileiros (AGB), Associação Brasileira de Climatologia (ABClima), União de
Geomorfologia Brasileira (UGB) e da Universidade Federal do Rio Grande do Norte (UFRN). O simpósio, que contou com a participação de inscritos de várias partes do Brasil, com artigos publicados referentes a quase todos os Estados brasileiros e o Distrito Federal, foi dividido em 11 eixos temáticos para apresentação de trabalhos, a saber: 1 - Cartografia, Geotecnologias e Geografia Física; 2 - Geografia e Turismo: desenvolvimento e meio ambiente; 3 - O meio físico e a degradação ambiental; 4 - Dinâmica, ocupação e impactos em ambientes costeiros; 5 - Geografia Física e a dinâmica da paisagem brasileira; 6 - A Caatinga e a desertificação no semi-árido brasileiro; 7 - Questões climáticas e recursos hídricos na região semi-árida brasileira; 8 - Cidades e Regiões Metropolitanas: a Geografia frente aos problema ambientais urbanos; 9 - A Geografia Física e a gestão das bacias hidrográficas; 10 - Geografia Física: gestão, política e educação ambiental; 11 - Pesquisa e ensino da Geografia Física com ênfase social e ambiental.

A programação de palestras, conferências e mesas-redondas foi bastante diversificada, com debates de temas polêmicos e com a participação de pesquisadores já consagrados. Foram proferidas quatro conferências: a de abertura, pelo Prof. Dr Jurandyr Luciano Sanches Ross, da USP, com o título "Ecogeografia no Planejamento Ambiental Territorial do Brasil"; a segunda intitulada de "O Aquecimento Global em Discussão", pelo Prof. Dr. José Bueno Conti, da USP; a terceira intitulada de "Ecologia da Paisagem", pelo Prof.

*Professor Doutor pelo Departamento de Geografia da FFLCH/USP. E-mail: egalvani@usp.br

**Geógrafa aluna de pós-graduação em Geografia Física pelo Departamento de Geografia da FFLCH/USP. E-mail: nadiagilma@yahoo.com.br 
Dr. Helmutt Troppmair, da UNESP-RC-SP e a conferência de encerramento, intitulada "O futuro da Geografia Física", pelo Prof. Dr. José Manuel Mateo Rodriguies, da Universidade de Havana.

As mesas redondas foram compostas por pesquisadores das diversas universidades participantes do evento, sempre com a preocupação de trazer diferentes visões de determinados assuntos. Foram realizadas um total de 13 mesas redondas, a saber: 1) Cartografia, Geotecnologias e Geografia Física; 2) Geografia e Turismo: desenvolvimento e meio ambiente; 3) Pesquisa e Ensino da Geografia Física com ênfase social e ambiental; 4) Geografia Física e a dinâmica da paisagem brasileira; 5) Dinâmica, ocupação e impactos em ambientes costeiros; 6) A caatinga e a desertificação no semi-árido brasileiro; 7) Questões climáticas e recursos hídricos na região Semi-árida brasileira; 8) A Geografia Física e a gestão das bacias hidrográficas; 9) Cidades e Regiões Metropolitanas: a Geografia frente aos problemas ambientais urbanos; 10) Geografia Física: gestão, política e educação ambiental; 11) O meio físico e a degradação ambiental; 12) Ética profissional na Geografia; 13) Mesa redonda especial promovida pela ABClima: Mudanças climáticas e saúde. Durante o evento foi ministrada, ainda, a palestra "Bases para construção da tipologia da Política Nacional de Desenvolvimento Regional, e dos Planos de Desenvolvimento Regional MacroRegionais", além de uma homenagem ao Prof. Dr Helmut Troppmair da UNESP - Rio Claro pela sua contribuição, ao longo da vida, à Ciência Geográfica.

Os participantes do simpósio puderam também escolher um mini-curso para participar. Os temas abordados e os professores responsáveis são apresentados a seguir: 1) Sensoriamento remoto aplicado a Geografia Física - Prof. Dr. Gustavo M. de M. Baptista (UCB); 2) Geoecologia da Paisagem - Prof. Dr. Edson Vicente da Silva (UFC); 3) Geomorfologia no ensino da Geografia Física para o ensino médio - Prof. Dr. Lucivânio Jatobá (UFPE); 4) Sistema de Informação Geográfica aplicado à análise ambiental - Prof.
Dr. Paulo César de Araújo (UFRN); 5) Arenização no sudoeste do Rio Grande do Sul e a desertificação no Nordeste Brasileiro - Profa. Dra. Dirce Suertegaray (UFRGS); 6) Uso turístico de recursos naturais: impactos ambientais, custos sociais - Profa. Dra Rita Ariza Cruz (USP); 7) Planejamento Ambiental - Prof. Dr. José Manuel Mateo Rodriguez (Universidade de Havana); 8) Qualidade Ambiental Urbana e Mudanças Climáticas - Profa. Dra. Magda Lombardo (UNESPRio Claro); 9) Planejamento ambiental e gestão do turismo - Prof. Dr. Giovanni Seabra (UFPB); 10) Elaboração de perfil integrado para análise e interpretação da paisagem - Profa. Dra. Daria Maria Cardoso (UFBA); 11) Abordagem sócioambiental urbana: uma introdução - Prof. Dr. Francisco Mendonça (UFPR); 12) Dinâmica costeira - Profa. Dra. Silvana Moreira Neves (UFPE); 13) Evolução geomorfológica da província da Borborema no nordeste brasileiro - Prof. Dr. Allaoua Saadi (UFMG); 14) Observar, sentir e interpretar a paisagem: a Geografia e a prática turística - Profa. Dra. Maria Geralda Almeida (UFG); 15) Paisagem - Prof. Dr. Roberto Verdum (UFRGS).

A comissão organizadora ainda providenciou três viagens de estudo para os participantes interessados, tendo como destino a Região Metropolitana de Natal, a Região do litoral sul do estado do RN, com dunas, mata atlântica, manguezais e viveiros de camarão; a Região do litoral norte do estado do RN, com dunas, manguezais e salinas e para a Região do Sertão e Caatinga.

O confronto das opiniões e as discussões ocorridas durante o evento, bem como durante as mesas redondas, painéis e comunicações orais, contribuíram para o avanço da Ciência Geográfica, construindo uma melhor compreensão das fragilidades da natureza, distribuídas ao longo do território brasileiro.

$\mathrm{Na}$ sessão de encerramento do evento, foi anunciada a sede do XIII SBGFA, em 2009, que será em Minas Gerais, com organização da Universidade Federal de Viçosa - UFMG.

Trabalho enviado e aceito em agosto de 2007 